Brit. J. industr. Med., 1964, 21, 187.

\title{
DESIGN AND EVALUATION OF A VENTILATED GARMENT FOR USE IN TEMPERATURES UP TO $200^{\circ} \mathrm{C}$.
}

BY

\author{
G. W. CROCKFORD and R. F. HELLON
}

From the M.R.C. Environmental Physiology Research Unit, London School of Hygiene and Tropical Medicine,
University of London

(RECEIVED FOR PUBLICATION JANUARY 14, 1964)

The protection of personnel against high air and radiant temperatures is a problem that has been confronting industry for many years now, and for many industrial situations it still has not been solved. The experiments reported here were intended to determine the most suitable form of insulation for a hot entry suit for use primarily in furnace wrecking where mean radiant temperatures of $200^{\circ} \mathrm{C}$. are met and where heat-reflecting garments are unsuitable due to the rapid deterioration of the reflecting surface.

From a preliminary consideration of the problem it was concluded that a ventilated garment was required and that conventional ventilated garments in which air is induced to flow parallel to the body surfaces (axial ventilation) are basically unsound in design as the air is not utilized for the transfer of heat in the most efficient manner. A new form of ventilation was therefore developed in which air flows out through a permeable suit (radial ventilation). This form of ventilation produces what is called dynamic insulation, and this method of insulation, when compared with two alternative methods on a physical model, was found to be very effective.

The model experiments were confirmed by comparative trials of three ventilated suits each using one of three different forms of insulation thought to be suitable for use in heat-protective clothing.

Physiological measurements made on the subjects and physical measurement made on the suits confirmed that dynamic insulation is the most suitable insulation for a hot entry suit for furnace wrecking.

With the air flows used in these experiments, dynamic insulation had a thermal conductance one-fifth that of conventional static insulation, and sweat losses and oral temperature rises were reduced by one-third and one-half respectively.

There are many situations in industry and in the Forces in which men are exposed to heat and which are severe enough to overload the human temperature regulation system. The inevitable consequence of this is that work can only be performed for very short periods dependent upon the heat storage capacity of the body. The worker then has to move into a cool environment in order to lose the 'stored' heat. If, however, a layer of insulation is provided which reduces the flow of heat from the environment to the man and at the same time cool air is circulated over the skin, the external heat load is considerably reduced and the man is provided with a microclimate in which he is able to regulate his body temperature.
Ventilated garments have been used on a small scale to alleviate thermal stress in the Forces and some sectors of industry for many years. However, the fact that the use of ventilated garments is very limited indicates that their present design may be inadequate and that their possibilities are not fully appreciated.

The present work was undertaken for the British Iron and Steel Research Association with the aim of protecting men who are exposed to severe heat in the steel industry. A survey of various hot situations in the industry (Hellon and Crockford, 1959) showed that the most severe conditions were found where plant such as furnaces, converters, soaking pits, and mixers have to be demolished before being rebuilt. 
This work often has to be done as quickly as possible before the plant has cooled down. Measurements showed that men were liable to be exposed initially to radiant temperatures as high as $160^{\circ} \mathrm{C}$. with air temperatures of about $50^{\circ} \mathrm{C}$. These values fall, of course, as the structure cools, but for several hours unprotected men can only work for brief periods. The experiments to be described were undertaken to provide effective protection for at least an hour in this demolition work, and although the design of ventilated suit which has emerged from these studies was to meet these high radiant conditions, the principle of the design can be used in almost any high temperature situation.

In the design of any ventilated suit for protection against heat, five main factors have to be considered: (1) the thermal environment, (2) the thermal resistance or conductance of the suit material, (3) the metabolic rate of the man wearing the suit, (4) the temperature, pressure, and quantity of air available or required, and (5) the work situation. Points (4) and (5) are mainly of a technical nature and have been considered elsewhere (Crockford, 1962a); the other three points, however, do have a direct bearing on the design of a physiologically acceptable heatprotective garment.

It was decided that various possible forms of insulation should be tested in a heat-flow model to assess their suitability for use in a ventilated garment, and these tests are described in Part I of this paper. The most promising of the types of insulation were then made up as suits and tested under simulated laboratory conditions for a physiological evaluation; these experiments form Part II.

\section{PART I}

\section{Insulation}

There are four methods of insulation that can be used in a ventilated heat-protective garment. They are (1) a uniform layer of high thermal resistance; (2) a heat-reflecting outer layer; (3) an internal layer of material to reflect radiant heat, i.e. a radiant heat barrier; and (4) dynamic insulation.

As very little information was available on any of these methods under the conditions likely to be encountered in the steel industry, it was initially decided to assess their suitability by means of models. Since the third and fourth of the methods listed are not generally known, they will be described in detail.

Radiant Heat Barrier.-Heat can be transferred across a clothing assembly or fabric by conduction through the air and fabric material, and by radiation and convection currents across the air spaces. In an assembly of two sheets of fabric separated by a 'spacer', and with the air gaps not more than $7 \mathrm{~mm}$. across, heat transfer through the assembly is mainly restricted to conduction through the air and to radiation. The conductivity of the air changes, but not greatly, over the range of temperatures anticipated, and the rate of heat transfer by conduction across a $7 \mathrm{~mm}$. gap will bear a nearly linear relationship to the temperature gradient. The rate of heat transfer by radiation, however, increases rapidly as the gradient increases and is proportional to the difference between the fourth powers of the absolute temperatures of the two surfaces. Calculations (see below) indicate that a steep thermal gradient will be established across a suit under industrial conditions, and therefore this type of radiant heat barrier construction would theoretically be of value.

Dynamic Insulation (Radial Ventilation). - In dynamic insulation cool air passes through a fabric in the opposite direction to the flow of heat. Thus in a ventilated suit using this principle the air escapes by permeating through the fabric of the suit. This is in contrast to the usual axial ventilation in which the air flow is parallel to the body surfaces and escapes at specific points, such as the ankles, wrists, and neck. This method of providing dynamic insulation was first applied to a clothing model by Phizackerley and his colleagues (Phizackerley, 1958), who passed warm air into the model for protection against cold exposure. In the present context the situation is thermally reversed.

Dynamic insulation has an important advantage over axial ventilation in that the ventilating air is used not only to cool the man but also to dissipate heat flowing in from the surroundings. The air must leave the suit at a temperature approaching the suit surface temperature, in the present case about $120^{\circ} \mathrm{C}$. With axial ventilation, however, the maximum desirable exit air temperature is determined by the wearer's skin temperature, and this should not rise above $35^{\circ} \mathrm{C}$. If the temperature of the ventilating air rises above that of the skin, there will be convective heat transfer to the man instead of away from him.

\section{Materials and Procedure}

Three types of material were tested for thermal conductance. These were (1) a foamed plastic covered on both sides with neoprene-coated terylene (total thickness $6 \mathrm{~mm}$.) as used in at least one design of ventilated suit (Crockford, Hellon, Humphreys, and Lind, 1961); (2) a radiant heat barrier constructed from string vest material $3 \mathrm{~mm}$. thick covered on both sides by a layer of aluminium foil. The radiant heat barrier so formed was in turn covered on both sides by a thin cotton fabric; and 
(3) three materials that appeared suitable for dynamic insulation: (a) a light felt-like material (Fearnought T54), (b) a $6 \mathrm{~mm}$. thick 'double' cloth, i.e. an outer layer of worsted fabric woven with a raised woollen 'pile' inside, and $(c) 1 \mathrm{~cm}$. thick open-celled polyurethane foamed plastic.

Thermal conductance was determined by applying a standard intensity of radiant heat to one side of the material and measuring the temperature on both sides with 30 s.w.g. copper constantan thermocouples. The heat flow through the material was measured by means of a heat flow disc (Hatfield and Wilkins, 1950) fastened to the under side. The conductances reported here apply only under the present experimental conditions, since it was not possible to standardize all conditions of testing, such as pressure on the fabric.

For testing the impermeable foamed plastic and radiant heat barrier assemblies, two 6-in. square $(15.24 \mathrm{~cm}$. square) metal frames (exposed area 5 in. square $(12.7 \mathrm{~cm}$. square)) were used, the assemblies being sandwiched between the two frames.

For investigating dynamic insulation, a metal bin $(14 \times$ $14 \times 17$ in. $(35.56 \times 35.36 \times 43.18 \mathrm{~cm}$.) $)$ was used into which air could be fed, the rate of flow being monitored by a rotameter. The sample to be tested was secured across the top, with the thermocouples and heat flow disc mounted in the middle.

In all the tests, a $2 \mathrm{~kW}$. radiant heat panel $1 \mathrm{ft}$. square $(30.5 \mathrm{~cm}$. square) was used, mounted in a frame to ensure an identical geometric orientation of radiant heat source to sample. The heater voltage was set at a value which in preliminary tests had brought the surface of a piece of $6 \mathrm{~mm}$. thick double cloth to $160^{\circ} \mathrm{C}$. Extraneous air movements were kept to a minimum, and the measurements were taken when the system had reached equilibrium.

The choice of a temperature of $160^{\circ} \mathrm{C}$. was made on - the basis of surveys in steel plants (Hellon and Crockford, 1959), which had indicated that a mean radiant temperature (M.R.T.) of $200^{\circ} \mathrm{C}$. would be a realistic upper limit in which a ventilated suit would find employment. Under these conditions, air temperatures of up to $50^{\circ} \mathrm{C}$. and air velocities of 50 to $200 \mathrm{ft} . / \mathrm{min}$. (15 to $60 \mathrm{~m}$. $/ \mathrm{min}$.) had been found. With these data and making the assumption that no heat is flowing into the suit, an estimate of the outer surface temperature of a heat-protective garment can be made.

The surface temperature of a suit comes into equilibrium with its surroundings when the radiant heat gain equals convective heat loss. Values for radiant heat gain at differing suit surface temperatures were calculated and plotted. The convective heat loss at varying air speeds and suit surface temperatures was also calculated and graphed using the formula $C=2 \cdot 14 \sqrt{ } V \Delta t$ (Haines and Hatch, 1952), where $C$ is the heat loss in B.t.u./hr., $V$ is the air velocity in $\mathrm{ft}$./min., $\Delta \mathrm{t}$ is the difference between air and suit surface temperatures, and 2.14 is the coefficient of heat exchange by convection for a standing man, or in this case a suit of equal area to the man. If 0.534 is used as the co-efficient the answer is obtained in kcal.

Figure 1 shows the radiant heat gain in an M.R.T. of

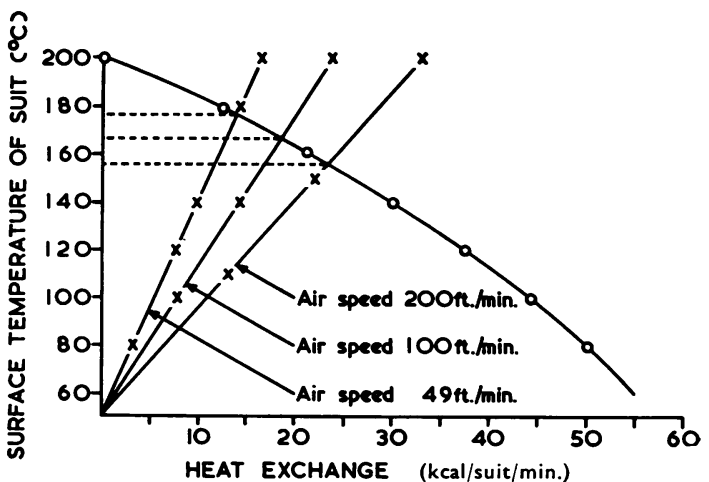

Fig. 1.-Theoretical effect of various possible suit surface temperatures on rate of heat gain by radiation $(O)$ and heat loss by convection (X). Convective loss has been calculated for three air speeds. At equilibrium the suit surface temperatures are indicated by the three points of intersection. M.R.T. $200^{\circ} \mathrm{C}$.; emissivity of suit 1 ; area of suit $1.8 \mathrm{~m}^{2}$; air temperature $50^{\circ} \mathrm{C}$.

$200^{\circ} \mathrm{C}$. and convective heat loss to air at a temperature of $50^{\circ} \mathrm{C}$. and with air velocities of 49,100 , and $200 \mathrm{ft}$. $/ \mathrm{min}$. The points of intersection give the suit surface temperatures to be expected at the different rates of convective loss. Field studies indicate that air movements in furnaces are variable but that $200 \mathrm{ft}$. $/ \mathrm{min}$. $(60 \mathrm{~m}$. $/ \mathrm{min}$.) is an average figure. Neglecting heat flow into the suit, a suit surface temperature of 150 to $160^{\circ} \mathrm{C}$. would be anticipated.

This value is important because it influences the choice of fabrics and indicates the maximum temperature gradient to be expected across the insulating material, in this instance about $120^{\circ} \mathrm{C}$.

\section{Results}

Foam Plastic Insulation.-The material was tested for thermal conductance with just sufficient pressure to keep the terylene layers in contact with the foamed plastic. The results are given in Table 1 .

The neoprene-coated terylene is non-reflecting, and so it was decided to investigate the effect of a cheap, easily applied reflecting surface on the temperature gradient across the material. The third set of results in Table 1 show the change that occurred in surface temperatures after an application of aluminium paint. The conductance is reduced slightly, but this was attributed to a change in the thickness of the air gaps between the neoprene and foamed plastic, the aluminium paint having made the neoprene stiff and less able to follow the contours of the foamed plastic.

Radiant Heat Barrier.-The assembly was mounted as previously described, and experiments were performed with the reflecting surface of the aluminium foil untreated. To assess the value of these low 
TABLE 1

CONDUCTANCES OF AN IMPERMEABLE FOAMED PLASTIC ASSEMBLY AND A RADIANT HEAT BARRIER AND CONTROL

\begin{tabular}{|c|c|c|c|c|c|}
\hline Sample & $\begin{array}{c}\text { Outer Surface } \\
\text { Temperature }\left({ }^{\circ} \mathrm{C} .\right)\end{array}$ & $\begin{array}{c}\text { Inner Surface } \\
\text { Temperature }\left({ }^{\circ} \mathrm{C} .\right)\end{array}$ & $\Delta \mathrm{t}^{\circ} \mathrm{C}$ & $\begin{array}{c}\text { Heat Flow } \\
\text { through Material } \\
\left.\text { (kcal./min./m. }{ }^{2}\right)\end{array}$ & $\begin{array}{c}\text { Conductance of } \\
\text { Sample } \\
\left.\text { (kcal./min./m. }{ }^{2} /{ }^{\circ} \mathrm{C} .\right)\end{array}$ \\
\hline $\begin{array}{l}\text { Foamed plastic } 6 \mathrm{~mm} \text {. thick bounded on } \\
\text { either side by neoprene-proofed terylene }\end{array}$ & $\begin{array}{l}152 \\
155 \\
117^{*}\end{array}$ & $\begin{array}{l}92 \\
94 \\
70\end{array}$ & $\begin{array}{l}60 \\
61 \\
47\end{array}$ & $\begin{array}{l}5 \cdot 6 \\
5 \cdot 8 \\
4 \cdot 1\end{array}$ & $\begin{array}{l}0.093 \\
0.095 \\
0.088\end{array}$ \\
\hline $\begin{array}{l}\text { Assembly of string vest material between } \\
\text { two sheets of aluminium foil covered } \\
\text { on outsides with cotton fabrics }\end{array}$ & $\begin{array}{l}152 \\
156 \\
167\end{array}$ & $\begin{array}{r}98 \\
100 \\
111\end{array}$ & $\begin{array}{l}54 \\
56 \\
56\end{array}$ & $\begin{array}{l}4 \cdot 39 \\
4 \cdot 12 \\
4 \cdot 85\end{array}$ & $\begin{array}{l}0.081 \\
0.073 \\
0.086\end{array}$ \\
\hline $\begin{array}{l}\text { As above, but with internal reflecting } \\
\text { layers blackened }\end{array}$ & $\begin{array}{l}154 \\
145 \\
110^{*}\end{array}$ & $\begin{array}{r}102 \\
101 \\
78\end{array}$ & $\begin{array}{l}52 \\
44 \\
32\end{array}$ & $\begin{array}{l}5 \cdot 20 \\
4 \cdot 30 \\
3 \cdot 23\end{array}$ & $\begin{array}{l}0 \cdot 100 \\
0.097 \\
0 \cdot 100\end{array}$ \\
\hline
\end{tabular}

* Outer surface treated with aluminium paint.

emissivity surfaces for reducing total heat transfer, the measurements were repeated with the inner surfaces blackened, so destroying the radiant heat barrier. The results given in Table 1 indicate that the radiant heat barrier has only a slightly lower thermal conductance than the same assembly with the aluminium foil blackened.

Dynamic Insulation.- The results of tests on three materials are shown in Table 2. T54 (Fearnought) proved to have a high conductance, and only the double cloth and the foamed plastic were investigated in detail using various rates of air flow.

The reduction in conductance with increasing ventilation was considerable and indicated that

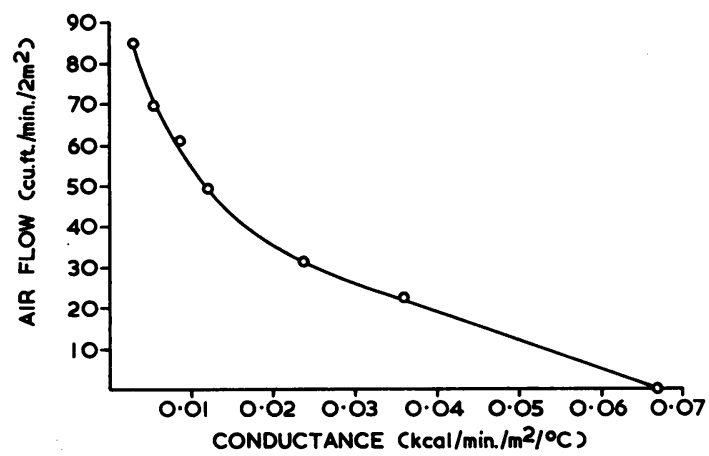

FIG. 2.-Relation between air flow through a foamed plastic, covered with cotton fabric on the outside, and its conductance.

TABLE 2

EFFECT ON THEIR CONDUCTANCES OF PASSING AIR THROUGH PERMEABLE MATERIALS

\begin{tabular}{|c|c|c|c|c|c|c|}
\hline Sample & $\begin{array}{c}\text { Air Supply* } \\
\text { (cu. ft./min./2m. }{ }^{2} \text { ) }\end{array}$ & $\begin{array}{c}\text { Outer Surface } \\
\text { Temperature }\left({ }^{\circ} \mathrm{C} .\right)\end{array}$ & $\begin{array}{c}\text { Inner Surface } \\
\text { Temperature }\left({ }^{\circ} \mathrm{C} .\right)\end{array}$ & $\Delta \mathrm{t}^{\circ} \mathrm{C}$ & $\begin{array}{c}\text { Heat Flow } \\
\text { through Material } \\
\left(\text { kcal./min./m. }{ }^{2}\right)\end{array}$ & $\begin{array}{c}\text { Conductance of } \\
\text { Sample } \\
\left.\text { (kcal./min./m. }{ }^{2} /{ }^{\circ} \mathrm{C} .\right)\end{array}$ \\
\hline T54 $2.5 \mathrm{~mm}$. thick & 49 & 124 & 75 & 49 & $7 \cdot 90$ & $0 \cdot 1608$ \\
\hline $\begin{array}{l}\text { Double cloth } 6 \mathrm{~mm} \text {. thick } \\
\text { and } 70 \mathrm{mg} . / \mathrm{cm}^{2}\end{array}$ & $\begin{array}{l}0 \\
30 \cdot 0 \\
46 \cdot 0 \\
49 \cdot 0 \\
61 \cdot 2 \\
61 \cdot 2 \\
68 \cdot 8 \\
76 \cdot 5\end{array}$ & $\begin{array}{l}162 \\
154 \\
146 \\
146 \\
141 \\
138 \\
137 \\
126\end{array}$ & $\begin{array}{r}114 \\
92 \\
82 \\
74 \\
64 \\
67 \\
60 \\
55\end{array}$ & $\begin{array}{l}48 \\
62 \\
64 \\
72 \\
77 \\
71 \\
77 \\
71\end{array}$ & $\begin{array}{l}7 \cdot 12 \\
6.65 \\
5.35 \\
5.61 \\
4.66 \\
4.43 \\
4.45 \\
3.05\end{array}$ & $\begin{array}{l}0.1380 \\
0.1073 \\
0.0825 \\
0.0773 \\
0.0628 \\
0.0610 \\
0.0602 \\
0.0425\end{array}$ \\
\hline $\begin{array}{l}\text { Foamed plastic uncovered } \\
1 \mathrm{~cm} \text {. thick and } \\
23 \mathrm{mg} \cdot / \mathrm{cm} .^{2}\end{array}$ & $\begin{array}{l}0 \\
49 \cdot 0 \\
61 \cdot 2\end{array}$ & $\begin{array}{l}158 \\
122 \\
108\end{array}$ & $\begin{array}{r}102 \\
47 \\
38\end{array}$ & $\begin{array}{l}56 \\
75 \\
70\end{array}$ & $\begin{array}{l}8 \cdot 27 \\
5 \cdot 20 \\
4 \cdot 13\end{array}$ & $\begin{array}{l}0.1485 \\
0.0682 \\
0.0575\end{array}$ \\
\hline $\begin{array}{l}\text { Foamed plastic as above } \\
\text { covered with a cotton } \\
\text { fabric, i.e. a duster }\end{array}$ & $\begin{array}{l}0 \\
23.0 \\
30.8 \\
49.4 \\
61.6 \\
69.6 \\
85.0\end{array}$ & $\begin{array}{l}165 \\
158 \\
154 \\
144 \\
132 \\
130 \\
114\end{array}$ & $\begin{array}{l}75 \\
52 \\
42 \\
30 \\
26 \\
26 \\
24\end{array}$ & $\begin{array}{r}90 \\
106 \\
112 \\
113 \\
106 \\
104 \\
90\end{array}$ & $\begin{array}{l}5.95 \\
3.77 \\
2.69 \\
1.485 \\
0.898 \\
0.592 \\
0.287\end{array}$ & $\begin{array}{l}0.0670 \\
0.0359 \\
0.0240 \\
0.0120 \\
0.0084 \\
0.0055 \\
0.0030\end{array}$ \\
\hline
\end{tabular}

* The figures quoted for the air supply are the equivalent values which would be used in a suit of area $2 \mathrm{~m} .^{2}$ 
dynamic insulation could be usefully applied for heat protection in a ventilated suit.

The uncovered foamed plastic was translucent to light, and it was thought likely that the infra-red radiation was penetrating the foam to some extent to be absorbed in the deeper layers. When this was prevented by placing a cotton fabric on the upper surface of the sample, the final set of results in Table 2 was obtained. It is evident that this additional layer decreased the unventilated conductance and also made the effect of ventilation more pronounced. In Fig. 2 these results are shown in graphical form. Conductance decreases linearly with increasing air flow up to flow rates of about $40 \mathrm{cu}$. ft. $/ 2 \mathrm{~m}^{2} . / \mathrm{min}$. $\left(1 \cdot 13 \mathrm{~m}^{3} / 2 \mathrm{~m} .{ }^{2} / \mathrm{min}\right.$.), and beyond this point the effectiveness of increasing ventilation falls off.

\section{Discussion}

From these preliminary laboratory experiments it is possible to assess the merits and demerits of the various methods of insulation likely to be employed in a ventilated suit, and to rank them. The problems met in the design of a ventilated suit for use in high radiant temperatures are complex, and before any one design can be selected it is essential that tests be carried out on men wearing several types of assembly in a real or simulated situation.

In the impermeable foamed plastic insulation, a material already used in suits with axial ventilation, an assessment of the maximum amount of heat that will enter a suit of $2 \mathrm{~m}^{2}{ }^{2}\left(21.5 \mathrm{ft} .{ }^{2}\right)$ in area can be made from the data in Table 1 if it is assumed that the environment is sufficiently hot to maintain an outer suit surface temperature of $155^{\circ} \mathrm{C}$. when heat is being lost to the interior, and that the inner surface of the suit is at $40^{\circ} \mathrm{C}$. Without aluminium paint on the outer surface, about $21 \mathrm{kcal} . / \mathrm{min}$. will have to be removed by the ventilating air, disregarding for the moment the man's output of some $4 \mathrm{kcal} . / \mathrm{min}$. With air entering the suit at $20^{\circ} \mathrm{C}$. and leaving at $40^{\circ} \mathrm{C}$., $21 \mathrm{kcal}$. would require just under $10 \mathrm{lb}$. $(4.5 \mathrm{~kg}$.) of air or about $120 \mathrm{cu} . \mathrm{ft} . / \mathrm{min} .\left(3.5 \mathrm{~m} .{ }^{3} / \mathrm{min}\right.$.). By painting the material with aluminium paint the third set of results in Table 1 was obtained. These results show reductions of $38^{\circ} \mathrm{C}$. in the surface temperature of the sample and of $28 \%$ in heat flow. Consequently as the heat flow into the suit is reduced by nearly one-third, from $21 \mathrm{kcal}$. to about $15 \mathrm{kcal} . / \mathrm{min}$., the quantity of air required is now in the region of $90 \mathrm{cu}$. ft. $/ \mathrm{min}$. $\left(2.5 \mathrm{~m} .{ }^{3} / \mathrm{min}\right.$. $)$.

It can be seen that a highly reflecting layer, such as a foil with a reflectivity of 90 to $95 \%$ instead of the 30 to $40 \%$ reflectivity of aluminium paint, would be of great value. However, in the light of past ex- perience in industry, it seems advisable to avoid highly reflecting surfaces that deteriorate rapidly. An unsuccessful attempt was made to provide a protective coating for aluminium foil and has been described previously (Crockford and Hellon, 1960). Because of this difficulty with highly reflecting surfaces, the possibility of using surfaces of lower reflectivity must be considered. The problem now becomes one of deciding on the degree of reflectivity required to make it worth while treating a ventilated suit, and whether it can easily be recoated and maintained at the required level inside a steel works. An infra-red reflectivity of $40 \%$, obtainable with an aluminium paint, would theoretically reduce the temperature gradient across the suit by about $20 \%$ in an M.R.T. of $200^{\circ} \mathrm{C}$. (Crockford and Hellon, 1960). If this degree of reflectivity can be maintained, then an appropriate reduction in the bulk and weight of the suit insulation could be made or the ventilating rate could be decreased.

Theoretical considerations indicate that an assembly using a radiant heat barrier should have a high thermal resistance combined with light construction. The experimental results in Table 1 indicate that with the model of a radiant heat barrier the conductance was only slightly less than that of the terylene-faced foamed plastic of comparable thickness. Furthermore, when the internal reflecting surfaces were blackened, conductance increased by only some $20 \%$ whereas an increase of $70 \%$ was expected on theoretical grounds. The apparent failure of the radiant heat barrier assembly to approach its theoretical possibilities is probably explicable as follows. A spacer was necessary to keep the reflecting surfaces apart, and this would conduct heat through the assembly irrespective of whether radiant transfer was proceeding. The string vest spacer used had a closed area of $25 \%$, and the heat conducted through this was probably an appreciable fraction of the total heat transfer through the model. Also, the string material masked $25 \%$ of the reflecting surfaces. Hence the proportion of total heat transfer by radiation was less than that in the theoretical example where no spacer was introduced. The inner surface temperature reached with the model $\left(100^{\circ} \mathrm{C}\right.$.) was much higher than could be allowed in an actual suit. However, with ventilation the inner temperature would be greatly reduced, but only in vivo experiments will show whether the reduction is adequate.

It is clear that a form of dynamic insulation may be very efficient. The results in Table 2 show that when the conductance of unventilated foamed plastic is compared with the value at an air flow of $50 \mathrm{cu}$. ft. $/ \mathrm{min} . / 2 \mathrm{~m} .{ }^{2}\left(1.41 \mathrm{~m} .3 / \mathrm{min} . / 2 \mathrm{~m}^{2}\right)$ there is more than a five-fold decrease. Table 2 also shows 
that the model had an inner temperature of only $30^{\circ} \mathrm{C}$. at $50 \mathrm{cu}$. ft. $\left(1 \cdot 41 \mathrm{~m}^{3}\right)$ and if this could be reproduced in an actual suit then it is probable that a garment made in this way would be suitable for the industrial situation described previously.

A direct comparison should not be drawn between the conductances of the 'double' cloth and the foamed plastic as it was very difficult to measure the temperature on the raised pile side of the cloth, and also the thickness of the materials differed. The results illustrate, however, that large increases in thermal resistance can be obtained by using radial ventilation across a permeable insulator which would normally rely for its effectiveness on the still air trapped within it.

It is concluded from these model experiments that the application of a form of dynamic insulation in a ventilated suit may be the most efficient method of protecting men from excessive heat loads under the working conditions met in the steel industry. However, a decision on the selection of the most suitable suit can only be made on the basis of simulated studies, in which the various types of suit are compared.

\section{PART II}

\section{Laboratory Comparison of Four Ventilated Garments}

Although the experiments reported in Part I and in a later investigation (Crockford, 1962b) give a clear indication that dynamic insulation is the most effective among the various methods tested, it does not necessarily follow that the results of these model experiments can be extrapolated to the performance of a complete garment. There are many factors that affect the functioning of a suit which cannot easily be simulated in a physical model. These factors include the movements of the wearer, his heat production, sweating, and compression of the material at points of flexion. It was therefore essential to compare the different insulating systems as suits under standardized conditions, using both physical and physiological observations.

\section{Materials and Procedure}

Ventilated Suit Assemblies.-Four types were tested: (1) a permeable suit made from $1 \mathrm{~cm}$. thick polyurethane foamed plastic bounded on each side by a layer of cotton fabric. The ankles and wrists were a tight fit to prevent air escaping at these points; (2) an impermeable suit made from $1 \mathrm{~cm}$. thick polyurethane foamed plastic bounded on each side by impermeable neoprene-proofed terylene; (3) a radiant heat barrier suit constructed from two layers of aluminized fabric, aluminium layers facing each other, separated by a spacer of string vest material. The spacer held the two layers approximately $1 \mathrm{~cm}$. apart; and (4) a suit identical with No. 3 above but constructed without the reflecting layers.

Gloves, Boots, and Helmet.-Asbestos gloves and safety boots were worn with all the suits but neither were ventilated. To prevent the extremities becoming painful, it was found necessary to wrap the gloves and boots with aluminium foil. Later experiments, not reported here, showed that the problem could be solved with a simple ventilating system to the boots and gloves. A helmet constructed from foamed plastic and cotton fabric with a double-layered terylene visor, the outer terylene layer being gold coated, was used with all four suits. The helmet completely enclosed the head and was fastened to the suit.

Ventilating System and Air Supply.-The ventilating system used in all the experiments was similar to one that has been described previously (Mauch, Hall, and Klemm, 1955; Crockford et al., 1961).

Briefly, the system was constructed from a double layer of plastic sheet (polythene) which covered the trunk and legs but not the arms. Air blown into the space between the two layers of plastic emerged at pinholes distributed all over the inner layer of plastic and played on to the man's skin. A number of large holes passing through both layers of plastic permitted the air to escape to the space between the ventilated garment and the ventilating system. The arms and head were supplied with air by pipes attached to the double-layered distribution system. Air entered at waist level and, at the flow rates used in these experiments, produced a certain amount of ballooning of the garment.

All the suits were tested with a standard air supply of $45 \mathrm{cu} . \mathrm{ft} . / \mathrm{min} .\left(1 \cdot 3 \mathrm{m.}{ }^{3} / \mathrm{min}\right.$.) at a temperature, measured at the point of entry to the suit, of 22 to $23^{\circ} \mathrm{C}$. When investigating the skin temperature and the heat flow into the suits, a number of other air flows was used in addition to the standard condition. Details of these are given in the appropriate section.

Radiant Heat Chamber.-The chamber was designed to simulate conditions found in the steel industry, i.e. to provide about $200^{\circ} \mathrm{C}$. M.R.T. and $50^{\circ} \mathrm{C}$. air temperature. It was basically a 7-ft. cube with one wall hinged to form a door. The walls were of two layers of aluminium sheet separated by a 4 -in. $(10 \mathrm{~cm}$.) gap filled with vermiculite. Electric heating pads $(6 \times 6 \mathrm{ft} .(1.8 \times 1.8 \mathrm{~m}$. $))$ were hung behind the four inner walls, each dissipating $8 \mathrm{~kW}$. In addition, four $2-\mathrm{kW}$. electric fires were placed in the corners of the chamber. The roof was only partial, and this allowed the subject to be viewed and also permitted convection currents to escape. Measurements in the centre of the chamber showed a radiant temperature of $190^{\circ} \mathrm{C}$. with an air temperature of $72^{\circ} \mathrm{C}$. Measurements of air movement with an ionization anemometer indicated that this was about $50 \mathrm{ft} . / \mathrm{min}$. $(15 \mathrm{~m} . / \mathrm{min}$.).

Work Routine.-The normal industrial energy expenditure for an eight-hour shift is about $4-5 \mathrm{kcal} . / \mathrm{min}$. (Lehmann, 1958; Murrell, 1960). With subjects who were 
not accustomed to manual work it was thought advisable to simulate this energy expenditure with a step-climbing routine and not with a work task involving the arm and back muscles, as is the case in furnace wrecking. Climbing a 1 -ft. $(30.5 \mathrm{~cm}$.) step 12 times a minute for 25 minutes followed by 5 minutes' rest gives an approximate energy expenditure of $4.5 \mathrm{kcal} . / \mathrm{min}$. (Macpherson, 1960) and this was selected as a suitable work routine. The exact energy expenditure varied, of course, with the subject's weight, but since the main comparisons have been made between suits on the same individual this was of no great consequence.

Subjects and Conditions of Exposure.-Five members of the laboratory staff acted as subjects. The suit incorporating a radiant heat barrier was found to be very heavy compared with the other two suits, and on this count it was discarded as a possibility for use in hot repair work after two runs. Likewise, only two runs were carried out in the control suit. All five subjects were exposed for one hour in both the permeable and impermeable suits. In addition, two of the subjects worked for a two-hour period in the permeable suit. A subject was not exposed more than once in any one week, and this avoided any cumulative heat acclimatization.

Experiments were performed under as near standard environmental conditions as is possible with the hot chamber (globe and air temperature of $157^{\circ} \mathrm{C}$. and $72^{\circ} \mathrm{C}$. respectively). The subject entered the cubicle and after standing for $5 \mathrm{~min}$. commenced the work routine over the next $25 \mathrm{~min}$. A 5 -min. rest period in the cubicle was then taken with the subject remaining standing. He then worked for a further $25 \mathrm{~min}$. and finally rested $5 \mathrm{~min}$. in the cubicle.

Physiological and Physical Measurements.-Physiological measurements consisted of oral temperatures (30 s.w.g. copper-constantan thermocouple placed under the tongue) and total weight loss (nude) during the exposure. Skin temperature measurements at 13 sites were made on one subject in the permeable and impermeable suits by means of $30 \mathrm{s.w.g}$. thermocouples mounted on an elastic harness. The tension in the harness was adjusted so that the wire just indented the skin.

Air temperatures were measured with thermocouples between the ventilating garment and the skin in the following regions: leg, back, chest, and helmet. Wet and dry bulb temperatures between the chest and the ventilating garment were recorded during a number of runs with a small hygrometer (Christie, Gleeson, Jowett, and Wright, 1957).

The temperature of both the inner and outer suit surfaces was measured on the lower thigh, arm, chest, back, and helmet during each run with thermocouples. The heat flow into the suit was measured during one run on each suit using Hatfield heat flow discs.

\section{Results}

Comparison of Permeable and Impermeable Suits. In five pairs of experiments in which the permeable
TABLE 3

SWEAT RATES AND RISE IN ORAL TEMPERATURE IN SUBJECTS WEARING PERMEABLE AND IMPERMEABLE SUITS

\begin{tabular}{|c|c|c|}
\hline Subject & Permeable Suit & Impermeable Suit \\
\hline R.F.H. & $\begin{array}{l}7.01 \mathrm{~g} . / \mathrm{min} . \\
0.99 \% / \mathrm{hr} .\end{array}$ & $\begin{array}{c}11.6 \mathrm{~g} / \mathrm{min} . \\
2.41^{\circ} / \mathrm{hr} .\end{array}$ \\
\hline G.W.C. & $\begin{array}{l}8.97 \mathrm{~g} / \mathrm{min} . \\
1.09 \% \mathrm{hr} .\end{array}$ & $\begin{array}{l}12.4 \mathrm{~g} . / \mathrm{min} \\
1.9 \% \mathrm{hr} .\end{array}$ \\
\hline G.W.C. & $\begin{array}{l}8.4 \mathrm{~g} \cdot / \mathrm{min} . \\
0.99 \% \mathrm{hr} .\end{array}$ & $\begin{array}{l}12.0 \mathrm{~g} . / \mathrm{min} \\
1.55^{\circ} / \mathrm{hr} .\end{array}$ \\
\hline D.P.M. & $\begin{array}{l}8.8 \mathrm{~g} . / \mathrm{min} . \\
0.85^{\circ} / \mathrm{hr} \text {. }\end{array}$ & $\begin{array}{c}14 \cdot 7 \mathrm{~g} / \mathrm{min} . \\
2.5^{\circ} / \mathrm{hr} .\end{array}$ \\
\hline W.G.B. & $\begin{array}{l}14.5 \mathrm{~g} . / \mathrm{min} . \\
1.68^{\circ} / \mathrm{hr} .\end{array}$ & $21 \cdot 2 \mathrm{~g} . / \mathrm{min}$. \\
\hline $\begin{array}{l}\text { Average sweat rate } \\
\text { Average rise in oral } \\
\text { temperature }\end{array}$ & $\begin{array}{l}9.53 \mathrm{~g} . / \mathrm{min} . \\
1.12 \% / \mathrm{hr} \text {. }\end{array}$ & $\begin{array}{l}14.38 \mathrm{~g} . / \mathrm{min} \\
2 \cdot 13^{\circ} / \mathrm{hr}\end{array}$ \\
\hline
\end{tabular}

suit was worn on one occasion and the impermeable suit on another, the rise of oral temperature and the sweat rate were lowest in the permeable suit. Individual results are given in Table 3 and show that this was the case in each of the five comparisons. On average the rate of rise of oral temperature was halved by wearing the permeable suit, and the sweat rate in this suit was only two-thirds of that in the impermeable garment. In neither suit did the subjects come into thermal equilibrium as judged by their oral temperatures. This point is illustrated for the permeable suit in Fig. 3 which shows the oral temperature changes in two subjects who worked in the chamber for two hours. The temperature fell slightly during rest periods but the upward trend continued for the whole exposure. However, even though equilibrium was not achieved in the perme-

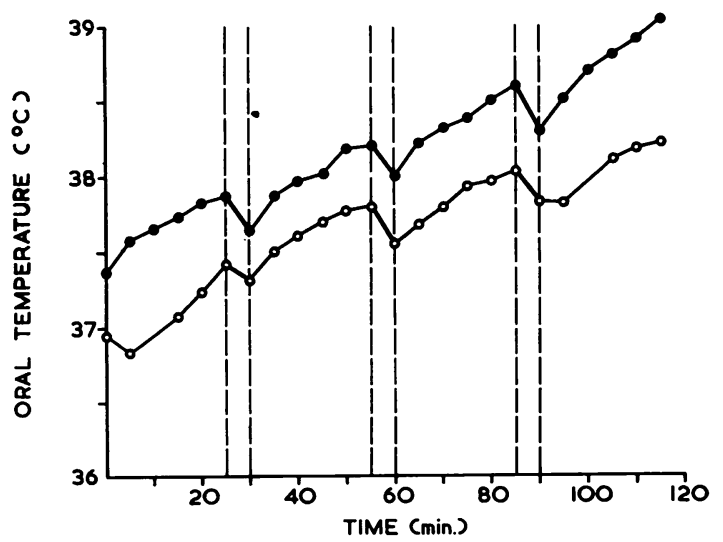

Fig. 3.-Oral temperatures of two subjects during a two-hour exposure in a permeable suit. The broken lines indicate rest periods. 
able suit, it is clear that exposure for two hours in the impermeable suit with twice the rate of temperature rise would have been impossible.

Skin temperatures measured on one subject during the second half of a one-hour exposure in the chamber were lower in the permeable than in the impermeable suit. Mean skin temperatures, weighted according to the different regions of the body (Newburgh, 1949), were $34^{\circ} \mathrm{C}$. and $36^{\circ} \mathrm{C}$. in the permeable and impermeable suits respectively.

During the five comparison experiments of Table 3 the inner and outer surface temperatures of the suits were measured with pairs of thermocouples on the arm, thigh, chest, and back. The values obtained were weighted according to the proportions of these areas as shown in a tailor's pattern for the suits. The mean weighted surface temperatures are given in Table 4 and show that, although both suits had similar outer surface temperatures, there was a difference of $12^{\circ} \mathrm{C}$. between the inner surface temperatures in favour of the permeable suit.

TABLE 4

MEAN WEIGHTED SURFACE TEMPERATURES OF TWO SUITS. COMBINED RESULTS FROM FIVE SUBJECTS

\begin{tabular}{l|c|c}
\hline & Inner Surface & Outer Surface \\
\hline Permeable suit & $37^{\circ} \mathrm{C}$. & $109^{\circ} \mathrm{C}$. \\
Impermeable suit & $49^{\circ} \mathrm{C}$. & $110^{\circ} \mathrm{C}$. \\
\hline
\end{tabular}

Air temperatures were measured at a number of points inside both suits. There was little difference in the temperatures, the mean values being $31^{\circ} \mathrm{C}$. for the impermeable suit and $29^{\circ} \mathrm{C}$. for the permeable. Humidity measurements over the chest with the small psychrometer gave vapour pressures of 14 and $18 \mathrm{~mm}$. $\mathrm{Hg}$ for the permeable and impermeable suits respectively.

In tests on one subject who stood without working

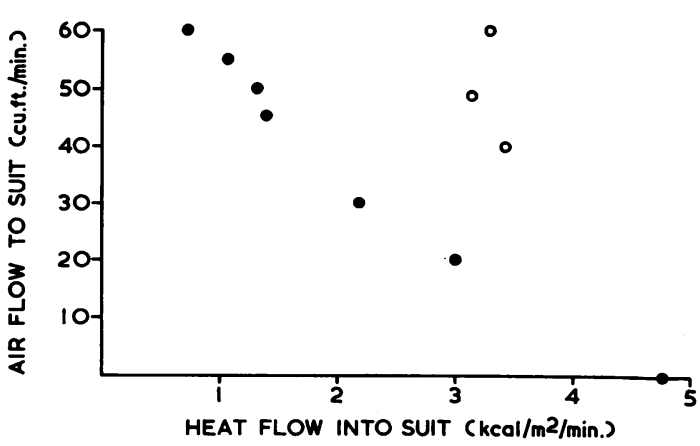

Fig. 4.-Effect of increasing ventilation on the mean heat flow into permeable and impermeable suits.

- Permeable suit; $\bigcirc$ impermeable suit. in the cubicle, heat flow into the two suits was measured at seven different sites with air flows varying from 0 to $60 \mathrm{cu}$. ft. $/ \mathrm{min}$. (0 to $1 \cdot 7 \mathrm{~m} .3 / \mathrm{min}$.). The average results are plotted in Fig. 4 and confirm the model experiments of Part $I$ in showing the large decrease in heat flow which is possible in dynamic insulation when the ventilation rate is increased. In contrast, the changes in heat flow into the impermeable suit were slight. Heat flow values for the impermeable suit were not obtained at low air flows as at least 20 minutes was required for each set of readings and this exceeded the endurance time of the subject under low air flow conditions.

Comparison of Suits with and without Radiant Heat Barrier.-As pointed out above, these suits were heavy and cumbersome and were only subjected to limited tests on one man. The findings will not be presented in detail. After two one-hour runs in each of the two suits, the physiological data showed no clear difference between them, and measurements of the inner surface temperatures of the suits confirmed this.

\section{Discussion}

The main objective of these experiments was to make tests of some of the types of insulation investigated in Part I in order to extend the model findings to actual suits worn by working subjects.

As in the model experiments, the radiant heat barrier did not even approach its theoretical possibilities. The reason for this failure is probably the constructional difficulty of maintaining a $1 \mathrm{~cm}$. gap between the two layers and ensuring that this air gap is static without convection currents. Movements of the subject would tend to increase convective heat transfer between the two aluminized layers, so reducing the relative importance of radiation as a channel of heat transfer across the suit and hence the influence of the aluminized surfaces on the total heat transfer. In addition to its insulative failure, the radiant heat barrier suit proved to be heavy and expensive to manufacture both in labour and materials.

The physical model experiments had demonstrated a marked superiority of dynamic over conventional insulation, but for many years it has been accepted that for the most efficient use of ventilating air, the air must flow parallel to the skin and not transversely through the outer clothing (Fetcher, Rapaport, Hall, and Shaub, 1949). Consequently, a clear demonstration of the practical advantage of radial air flow was required. It has also been generally accepted that in environments of high radiant temperatures reflective 
surfaces are required. Again a clear demonstration of the suitability of dynamic insulation for high radiant temperatures was needed.

Although permeable ventilated suits have already been investigated and used in industry (Brouha, 1955), none, to the authors' knowledge, have incorporated the principle of dynamic insulation. These suits are similar to a boiler suit and are made of permeable material to enable men to wear them without discomfort while disconnected from the air supply. A comparison with impermeable clothing has not previously been made.

Both the physical and the physiological observations made with the permeable and impermeable types of suit have fully confirmed the efficiency of dynamic insulation which the model experiments of Part I demonstrated.

With an air supply into the permeable suit of $50 \mathrm{cu}$. ft. $/ \mathrm{min}$. $(1.4 \mathrm{~m} .3 / \mathrm{min}$. $)$, the mean conductance in the cubicle was $0.0186 \mathrm{kcal} . / \mathrm{m} .{ }^{2} / \mathrm{min} . /{ }^{\circ} \mathrm{C}$. ${ }^{*}$ The suit had a surface area of $2.56 \mathrm{~m} .^{2}$ and thus in terms of the units used in Fig. 2 the rate of air flow was 39 cu. ft. $/ 2 \mathrm{~m} .{ }^{2}\left(1 \cdot 1 \mathrm{~m} .{ }^{3} / 2 \mathrm{~m} .{ }^{2}\right)$. At this flow rate the model (Fig. 2) had a slightly lower conductance of $0.0175 \mathrm{kcal} . / \mathrm{m} .{ }^{2} / \mathrm{min} . /{ }^{\circ} \mathrm{C}$. The discrepancy is probably due to the fact that part of the air supply to the suit went to the helmet, so that the actual flow rate through the fabric would have been less than 39 cu. ft. $/ 2 \mathrm{~m}^{2}\left(1 \cdot 1 \mathrm{~m} .{ }^{3} / 2 \mathrm{~m} .{ }^{2}\right)$.

With the data available it is possible to make an approximate heat balance for a subject working in the cubicle wearing a permeable suit. With an air supply of $45 \mathrm{cu} . \mathrm{ft} . / \mathrm{min} .(1 \cdot 3 \mathrm{~m} .3 / \mathrm{min}$. $)$, heat flow into the suit was $1.37 \mathrm{kcal} . / \mathrm{m} .{ }^{2} / \mathrm{min}$., giving a total heat flow for a suit of surface area $2.56 \mathrm{~m} .{ }^{2}$ of $3.5 \mathrm{kcal} . / \mathrm{min}$. The total heat gain of the microclimate in the suit is therefore made up of this factor plus the wearer's heat production, $4.5 \mathrm{kcal}$. $/ \mathrm{min}$. The total heat gain was thus $8.0 \mathrm{kcal} . / \mathrm{min}$. Heat losses from the microclimate consist of:

Evaporation of sweat $(9.5 \mathrm{~g} . / \mathrm{min}$.)

Heating of air supply from $22^{\circ}$ to $35^{\circ} \mathrm{C}$.

Heat storage by subject $(70 \mathrm{~kg}$., $\left.1 \cdot 12^{\circ} \mathrm{C} . / \mathrm{hr}\right)$

$5 \cdot 2 \mathrm{kcal} . / \mathrm{min}$.

$5 \cdot 2 \mathrm{kcal} . / \mathrm{min}$.

$1 \cdot 1 \mathrm{kcal} . / \mathrm{min}$.

$11.5 \mathrm{kcal} . / \mathrm{min}$.

The considerable difference of $3.5 \mathrm{kcal} / \mathrm{min}$. between these calculations is probably due in part to heat gain by the extremities and face as the following considerations show.

* Calculated from Table 5 (Crockford and Hellon, 1962).
The head, hands, and feet were not adequately protected in the cubicle tests, and some subjects complained of pain from the hands and feet; the face also felt very hot despite the gold coating on the visor. Although the discomfort was alleviated to some extent by the use of aluminium foil, the hands and feet were always very near the pain threshold after about 20 minutes in the cubicle. Each hand would have a blood flow of about $150 \mathrm{ml} . / \mathrm{min}$. (Clarke, 1958) and, with a hand skin temperature of $43^{\circ} \mathrm{C}$., the hands together could transfer about $1.5 \mathrm{kcal} . / \mathrm{min}$. from the environment to the man within the suit. If the feet and face each absorb heat at similar rates, a total of $4.5 \mathrm{kcal} . / \mathrm{min}$. could be transferred, and the discrepancy in the heat balance calculation would be resolved. While these calculations are probably not exact, they do serve to emphasize that heat absorbed in this way can form an appreciable fraction of the heat load that has to be dissipated by a subject under these conditions and show how important protection of the extremities can be.

In all the tests on human subjects the air distribution system consisted of a perforated double plastic layer. In the absence of ventilation, for example when waiting to enter a hot area, this is virtually a vapour barrier over most of the body surface and hence is quite uncomfortable. Also such a system is expensive to produce and has to be donned as a separate garment before the suit itself.

An alternative would be a simple system of perforated pipes which supplied air to each limb and to the trunk and head (helmet). These pipes would arise from a plastic manifold fixed inside the lumbar region of the suit, and the whole system would be fastened to the inner surface of the suit, so forming a complete ventilated garment.

Such a system has been tested in the permeable suit (Crockford and Hellon, unpublished) during six experiments on four subjects working for one hour in the cubicle. When compared with similar tests using the plastic layer distribution system, there were essentially no differences in terms of the subjects' sweat rates or oral temperatures. Thus in a practical situation a pipe system might be preferable in terms of comfort, simplicity, and cheapness.

The authors would like to thank Dr. J. Billingham and Mr. W. H. Rees for their helpful discussions, and Mr. G. Cashmore for technical assistance. The work reported in this paper forms part of a research programme being undertaken under contract to the British Iron and Steel Research Association and is submitted for publication with their kind permission. 


\section{REFERENCES}

Brouha, L. A. (1955). Transactions 20th Annual Meeting Industrial Hygiene Foundation, Mellon Institute.

Christie, G. S., Gleeson, J. P., Jowett, W. G., and Wright, A. S. (1957). Brit. J. industr. Med., 14, 258.

Clarke R. S. J. (1958) M.D. Thesis, Queen's University of Belfast. Crockford, G. W. (1962a). British Iron and Steel Research Association Report OR/HF/14/62.

Report OR/HF/14/62. OR/HF/13/62.

and Hellon, R. F. (1960). British Iron and Steel Research Association Report OR/HF/29/60.

- - (1962). British Iron and Steel Research Association Report OR/HF/51/62.

,- , Humphreys, P. W., and Lind, A. R. (1961). Ergonomics,

Fetcher, E. S., Rapaport, S. I., Hall, J. F., and Shaub, H. G. (1949). J. appl. Physiol., 2, 49.
Haines, G. F. and Hatch, T. (1952). Heating and Ventilating, 49, no. 11, p. 93 .

Hatfield, H. S., and Wilkins, F. J. (1950). J. sci. Instrum., 27, 1.

Hellon, R. F., and Crockford, G. W. (1959). British Iron and Steel Research Association Report OR/HF/46/59.

Lehmann, G. (1958). Ergonomics, 1, 328

Macpherson, R. K. (Ed.) (1960). Physiological Responses to Hot Environments. Spec. Rep. Ser. med. Res. Coun. (Lond.), No. 298 , p. 154

Mauch, H. A., Hall, J. F., and Klemm, F. K. (1955). A ventilating system for clothing. WADC Technical Report No. 55-152, Wright Air Development Center, Air Research and Development Command. Wright-Patterson Air Force Base, Ohio.

Murrell, K. F. H. (1960). Ergonomics, Fitting the Job to the Worker. p. 79. British Productivity Council.

Newburgh, L. D. (Ed.) (1949). Physiology of Heat Regulation, p. 248. Saunders, Philadelphia.

Phizackerley, P.J. R. (1958). Air Ministry Flying Personnel Research Committee Report FPRC 1026. 